\title{
Evaluation of Genetic Variation Among Wild Populations and Local Varieties of Rice
}

\author{
Takashige Ishii • Takashi Hiraoka • \\ Tomoyuki Kanzaki • Masahiro Akimoto • \\ Rieko Shishido • Ryo Ishikawa
}

Received: 21 October 2011 / Accepted: 1 November 2011 /Published online: 19 November 2011

(C) Springer Science+Business Media, LLC 2011

\begin{abstract}
Cultivated rice (Oryza sativa L.) is derived from Asian wild rice (Oryza rufipogon Griff). Vietnamese local varieties and wild natural populations in Vietnam and Myanmar were examined to evaluate the levels of genetic variation in cultivated and wild rice. In total, 222 Vietnamese local varieties were analyzed with ten microsatellite markers. Using marker genotype and gene diversity data, the local varieties were differentiated based on geographical distribution, cropping season, and human preference. A total of 976 wild plants were collected at six natural sites of wild populations (three each in Myanmar and Vietnam), and the degrees of variation among populations were analyzed with five microsatellite markers. Phylogenetic analyses revealed wide genetic differentiation among wild populations. The diversity values detected in a single wild population in Vietnam were higher than those in whole Vietnamese local varieties. These results indicate that wild rice has much greater genetic variation than cultivated rice.
\end{abstract}

Keywords Genetic variation · Rice · Local variety - Wild rice (Oryza rufipogon)

T. Ishii $(\triangle) \cdot$ T. Hiraoka $\cdot$ T. Kanzaki $\cdot$ R. Ishikawa Graduate School of Agricultural Science, Kobe University, Rokkodai, Nada-ku,

Kobe 657-8501, Japan

e-mail: tishii@kobe-u.ac.jp

\section{Akimoto}

Obihiro University of Agriculture and Veterinary Medicine, Inada,

Obihiro 080-8555, Japan

R. Shishido

College of Bioresource Science, Nihon University,

Kameino,

Fujisawa 252-8510, Japan

\section{Introduction}

Most crop species were originally derived from wild species. In the early days of domestication, primitive farmers may have unconsciously chosen desirable plants based on several simple traits related to shattering habit, seed dormancy, and seed size. However, the domestication and selection process led to a rapid reduction in the genetic diversity of crop species (Tanksley and McCouch 1997). Wild species maintain many genes that have been lost during domestication. Among them, trait-improving quantitative trait loci from wild relatives have been identified in various crops (Xiao et al. 1996, 1998; Tanksley et al. 1996). Such studies suggest that wild species still maintain many beneficial alleles for future plant breeding.

Oryza rufipogon is the ancestral wild species of cultivated rice, Oryza sativa (Oka 1988). They share the same AA genome and show high levels of cross compatibility. Therefore, O. rufipogon may be the most important wild genetic resource for rice breeding programs, because its useful genes can be easily transferred by crossing. Although cultivated rice has less genetic variation than wild rice, local varieties have maintained many useful traits. Local varieties are cultivated forms developed by adaptation to the natural and cultural environment in each area and are more genetically diverse than modern breeding varieties.

Molecular markers have become powerful tools for investigating genetic diversity among crop species. In particular, microsatellite or simple sequence repeat (SSR) markers are useful for revealing intra- and inter-specific variation because they are codominant with high levels of allelic diversity (McCouch et al. 1997). Microsatellites are tandemly arranged repeats of short DNA motifs (1-4 bp in length) that frequently exhibit variation in the number of 
repeats at a locus (Temnykh et al. 2001). Therefore, we used microsatellite markers to evaluate genetic variation in rice.

First, we analyzed 222 local varieties originated from various areas in Vietnam. They were collected more than 50 years ago by the late Prof. Hamada, Hyogo University of Agriculture, Japan, during a scientific expedition to Indo-China. They are suitable materials for analyzing genetic variation among local varieties before introducing modern breeding methodologies. As for wild species of $O$. rufipogon, many studies have been conducted to reveal the genetic differentiation among Asian accessions (Ishii et al. 2001; Sun et al. 2002; Cai et al. 2004). They usually used seed/plant materials derived from wild rice accessions maintained in germplasm institutes or seed banks, but these accessions do not represent the features of natural wild rice. Wild natural populations in southern China were investigated by several research groups (Song et al. 2003; Zhou et al. 2003; Gao 2004); however, those in the major distribution area of $O$. rufipogon have never been analyzed in detail. In this study, a large-scale survey on wild rice was carried out using 976 individuals from six natural populations in Myanmar and Vietnam, and genetic variation among wild rice populations was evaluated. In addition, the degree of genetic variation in wild rice was compared with that in local varieties.

\section{Materials and methods}

\section{Local varieties}

In total, 222 Vietnamese local rice varieties were used (Table 1). They were collected by the late Prof. Hamada, Hyogo University of Agriculture, in 1957 and 1958. Their origins and ecological characteristics were described in a research report titled "Rice in Mekong Valleys" by Hamada (1965). At the time of collection, Vietnam comprised North

Table 1 Vietnamese local varieties used in this study

\begin{tabular}{lll}
\hline Region & Group $^{\text {a }}$ & Number of varieties \\
\hline North & Fifth month rice & 35 \\
& Tenth month rice & 37 \\
& Glutinous rice N & 14 \\
South & Early rice & 33 \\
& Half season rice & 27 \\
& Season rice & 53 \\
& Late rice & 12 \\
& Glutinous rice S & 11 \\
Total & & 222 \\
\hline
\end{tabular}

${ }^{a}$ Classified by Hamada (1965) and South Vietnam. According to the report, North Vietnam local varieties were classified into two groups, "Fifth month rice" and "Tenth month rice". The former was grown during the dry season, whereas the latter during rainy season. South Vietnam local varieties were divided into several groups based on the growing period during the rainy season and seed characters ("Early rice", "Half season rice", "Season rice", "Late rice", and "Glutinous rice"). Hamada (1965) classified "Glutinous rice" as South Vietnam varieties; however, half of them came from North Vietnam according to the collection sites. Therefore, in this study, "Glutinous rice" was further divided into two groups, "Glutinous rice N" and "Glutinous rice S" for North and South Vietnam, respectively.

\section{DNA extraction}

Total DNA of the local variety was extracted from seed specimen. For each variety, the embryo segment was removed from a single seed and ground in $100 \mu \mathrm{l}$ of extracting solution containing $20 \mathrm{mM}$ Tris- $\mathrm{HCl}(\mathrm{pH} 8.0)$, $5 \mathrm{mM}$ EDTA, $400 \mathrm{mM} \mathrm{NaCl}, 0.3 \% \mathrm{SDS}$, and $200 \mu \mathrm{g} / \mathrm{ml}$ proteinase $\mathrm{K}$. The supernatant was used directly as the template for PCR.

Research sites for the wild rice populations

Research trips to collect wild rice were made to Myanmar in 2008 and Vietnam in 2007. Based on various population factors, such as ecotype (annual or perennial), size and degree of disturbance, three research sites each in Myanmar (PT-1, YG-23, and AK-18) and Vietnam (CT-61, CT-65, and CT-67) were established for wild rice observations (Fig. 1). Environmental and geographical information for these six observation sites is shown in Table 2.

\section{Wild rice sample collection}

At each site, leaves were collected from the different plants at 1-4-m intervals according to population size. In total, 976 wild natural plants from the six sites in Myanmar and Vietnam were surveyed. The number of samples ranged from 80 (CT-65) to 280 (YG-23), with an average of 162.6 (Table 2). The collected leaf samples were crushed with a wooden hammer, and the leaf extract was fixed on an FTA card (GE Healthcare). Samples were brought back to the laboratory, and small discs that were punched out from the FTA cards were used directly as PCR templates.

Polymorphism detection using SSR markers

Ten SSR markers (RM2, RM29, RM31, RM60, RM201, RM208, RM225, RM232, RM237, and RM241) were used. 
Fig. 1 Geographical location of the wild rice populations studied in Myanmar and Vietnam.

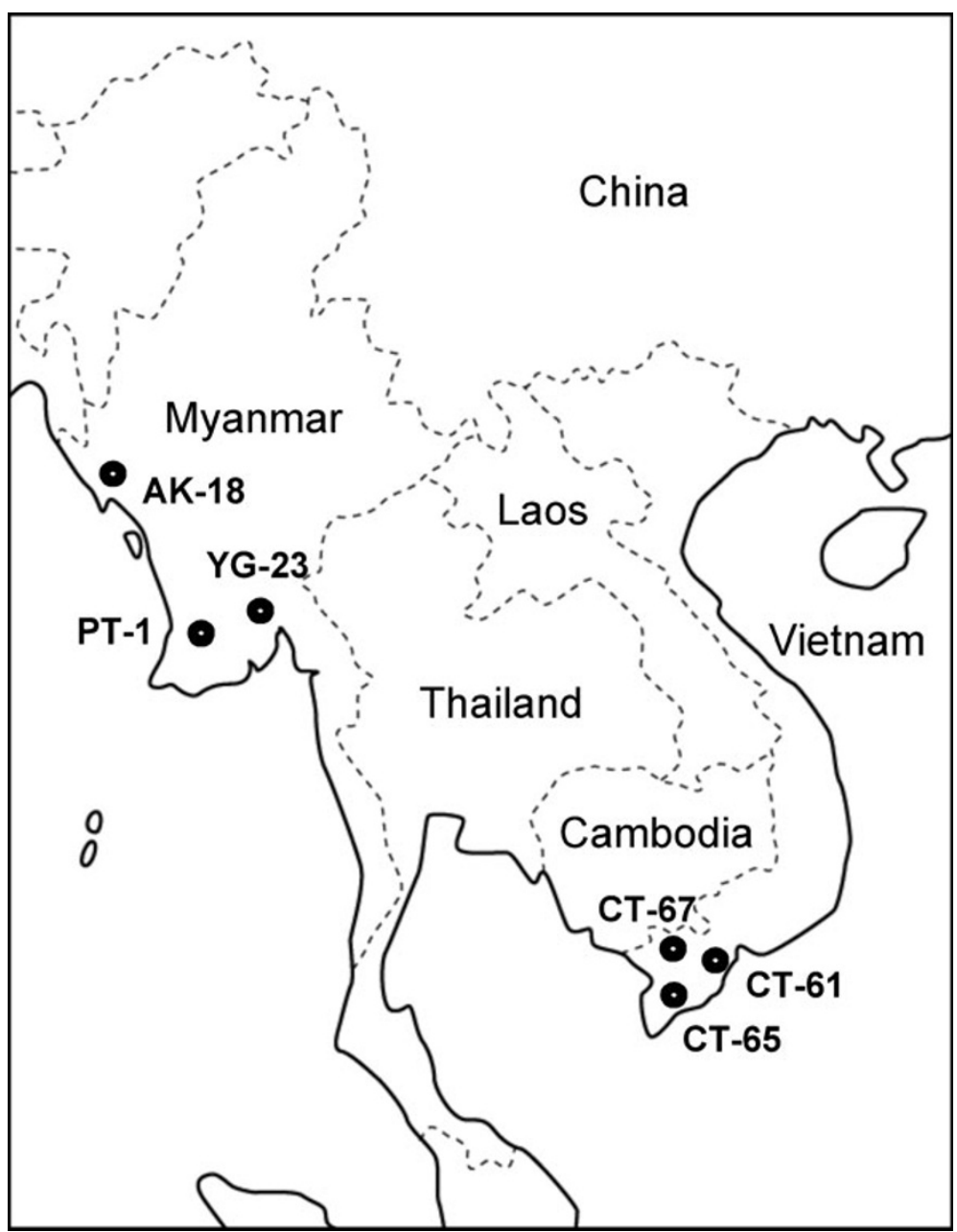

Of these, RM29 and RM208 are located on chromosome 2, and RM60 and RM232 on chromosomes 3. However, they are not linked because their map distances are much more than $50 \mathrm{cM}$ (Chen et al. 1997). Five SSR markers (RM31, RM60, RM201, RM208, and RM237) were used for the wild rice survey. PCR was performed in a 10-15 $\mu$ l mixture containing $1 \mu \mathrm{M}$ of each primer, a half volume of $2 \times$ Ampdirect plus buffer (Shimadzu, Japan), $1 \mu$ l of template DNA (or a small disc punched out from the FTA card), and
$0.5 \mathrm{U}$ of NovaTaq (Shimadzu, Japan). Amplification was performed with an MP Thermal Cycler (TaKaRa Bio, Japan) as follows: $94^{\circ} \mathrm{C}$ for $5 \mathrm{~min}$, followed by 35 cycles of $94^{\circ} \mathrm{C}$ for $1 \mathrm{~min}, 55^{\circ} \mathrm{C}$ for $1 \mathrm{~min}, 72^{\circ} \mathrm{C}$ for $2 \mathrm{~min}$, and ending with $5 \mathrm{~min}$ at $72^{\circ} \mathrm{C}$ for the final extension. The amplified products were electrophoresed on $4 \%$ polyacrylamide gels, and the banding pattern was visualized using a non-radioactive silver staining method, as described by Panaud et al. (1996).

Table 2 Site information on wild rice populations in Myanmar and Vietnam

\begin{tabular}{|c|c|c|c|c|c|c|}
\hline Site & Ecotype & Population size & Habitat & Number of samples & Latitude & Longitude \\
\hline \multicolumn{7}{|c|}{ Myanmar } \\
\hline PT-1 & Perennial & $>3 \mathrm{~km}$ & Deep water & 180 & $17^{\circ} 03^{\prime} 52.5^{\prime \prime}$ & $95^{\circ} 35^{\prime} 20.3^{\prime \prime}$ \\
\hline YG-23 & Perennial & c.a. $200 \mathrm{~m}$ & Road-side swamp & 280 & $17^{\circ} 08^{\prime} 49.1^{\prime \prime}$ & $96^{\circ} 17^{\prime} 28.4^{\prime \prime}$ \\
\hline AK-18 & Annual & c.a. $150 \mathrm{~m}$ & Paddy side & 156 & $20^{\circ} 15^{\prime} 02.7^{\prime \prime}$ & $92^{\circ} 49^{\prime} 13.9^{\prime \prime}$ \\
\hline \multicolumn{7}{|l|}{ Vietnam } \\
\hline CT-61 & Perennial & c.a. $250 \mathrm{~m}$ & Orange farm ditch & 140 & $10^{\circ} 20^{\prime} 45.8^{\prime \prime}$ & $105^{\circ} 56^{\prime} 06.7^{\prime \prime}$ \\
\hline CT-65 & Perennial & c.a. $3 \mathrm{~km}$ & Canal (discontinuous) & 80 & $09^{\circ} 46^{\prime} 48.9^{\prime \prime}$ & $105^{\circ} 38^{\prime} 02.9^{\prime \prime}$ \\
\hline CT-67 & Perennial & c.a. $1.5 \mathrm{~km}$ & Deep water & 140 & $10^{\circ} 42^{\prime} 43.8^{\prime \prime}$ & $105^{\circ} 30^{\prime} 16.1^{\prime \prime}$ \\
\hline
\end{tabular}


Table 3 Average dissimilarity values within Vietnamese local variety groups

\begin{tabular}{|c|c|c|c|c|c|c|c|c|c|}
\hline \multirow[t]{2}{*}{ Group } & \multicolumn{3}{|c|}{ North Vietnam } & \multicolumn{5}{|c|}{ South Vietnam } & \multirow{2}{*}{$\begin{array}{l}\text { Overall } \\
\text { means }\end{array}$} \\
\hline & Fifth & Tenth & Glu N & Early & Half & Season & Late & Glu S & \\
\hline Average dissimilarity & 0.32 & 0.49 & 0.44 & 0.45 & 0.41 & 0.42 & 0.41 & 0.47 & 0.51 \\
\hline
\end{tabular}

Fifth Fifth month rice, Tenth Tenth month rice, Early Early rice, Half Half season rice, Season Season rice, Late Late rice, Glu N Glutinous N, Glu $S$ Glutinous S

Evaluation of genetic variation within local variety groups and wild populations

Genetic variation within local variety groups was studied based on the dissimilarity of SSR electromorph allele sizes. The ratio of common fragments was calculated as a similarity index according to the following formula:

$F_{i j}=2 B_{i j} / A_{i j}$

where $A_{i j}$ and $B_{i j}$ are the number of total and common fragments, respectively, observed between $i$ th and $j$ th varieties (Nei and Li 1979). The dissimilarity of each variety pair was calculated as " $1-F_{i j}$ ". Genetic variation within rice group was examined based on their average dissimilarity indices.
Cultivated rice is a self-pollinating crop, whereas wild ancestral O. rufipogon is cross-pollinating. Therefore, genetic variation within groups (or populations) was also examined based on gene diversity, which can be applied to plants with any pollinating system (Nei 1987). The gene diversity values were calculated as follows:

$H_{i}=1-\sum_{j=1}^{n} x_{i j}^{2}$

where $x_{i j}$ is the frequency of the $j$ th allele for marker $i$, and the summation extends over $n$ alleles. This formula is the same as for calculating the expected heterozygosity for a random mating population, and the polymorphism information content (PIC) value for self-pollinating plants. The averages were used as overall gene diversity

Table 4 Number of alleles (A) and gene diversity value (B) observed for eight groups of Vietnamese local varieties

\begin{tabular}{|c|c|c|c|c|c|c|c|c|c|c|c|c|}
\hline \multirow[t]{2}{*}{ Group } & & \multicolumn{10}{|l|}{ Locus } & \multirow[t]{2}{*}{ Average } \\
\hline & & $\begin{array}{l}\text { RM2 } \\
\text { (Chr. 7) }\end{array}$ & $\begin{array}{l}\text { RM29 } \\
\text { (Chr. 2) }\end{array}$ & $\begin{array}{l}\text { RM31 } \\
\text { (Chr. 5) }\end{array}$ & $\begin{array}{l}\text { RM60 } \\
\text { (Chr. 3) }\end{array}$ & $\begin{array}{l}\text { RM201 } \\
\text { (Chr. 9) }\end{array}$ & $\begin{array}{l}\text { RM208 } \\
\text { (Chr. 2) }\end{array}$ & $\begin{array}{l}\text { RM225 } \\
\text { (Chr. 6) }\end{array}$ & $\begin{array}{l}\text { RM232 } \\
\text { (Chr. 3) }\end{array}$ & $\begin{array}{l}\text { RM237 } \\
\text { (Chr. 1) }\end{array}$ & $\begin{array}{l}\text { RM241 } \\
\text { (Chr. 4) }\end{array}$ & \\
\hline \multicolumn{13}{|l|}{ North Vietnam } \\
\hline Fifth month rice & A & 2 & 2 & 4 & 2 & 4 & 3 & 2 & 6 & 2 & 8 & 3.5 \\
\hline$(n=35)$ & B & 0.161 & 0.056 & 0.384 & 0.208 & 0.528 & 0.213 & 0.056 & 0.722 & 0.056 & 0.754 & 0.31 \\
\hline Tenth month rice & A & 3 & 1 & 3 & 2 & 4 & 4 & 4 & 7 & 6 & 7 & 4.1 \\
\hline$(n=37)$ & B & 0.152 & 0.000 & 0.569 & 0.497 & 0.505 & 0.554 & 0.608 & 0.663 & 0.627 & 0.711 & 0.49 \\
\hline Glutinous rice $\mathrm{N}$ & A & 2 & 2 & 3 & 2 & 4 & 4 & 4 & 5 & 2 & 4 & 3.2 \\
\hline$(n=14)$ & $\mathrm{B}$ & 0.426 & 0.459 & 0.592 & 0.444 & 0.582 & 0.582 & 0.604 & 0.722 & 0.426 & 0.556 & 0.54 \\
\hline \multicolumn{13}{|l|}{ South Vietnam } \\
\hline Early rice & A & 2 & 2 & 2 & 2 & 5 & 5 & 4 & 3 & 2 & 7 & 3.4 \\
\hline$(n=33)$ & B & 0.430 & 0.033 & 0.500 & 0.425 & 0.586 & 0.741 & 0.559 & 0.365 & 0.298 & 0.823 & 0.48 \\
\hline Half season rice & A & 1 & 1 & 4 & 2 & 4 & 5 & 3 & 7 & 4 & 8 & 3.9 \\
\hline$(n=27)$ & B & 0.000 & 0.000 & 0.469 & 0.403 & 0.403 & 0.781 & 0.366 & 0.618 & 0.350 & 0.806 & 0.42 \\
\hline Season rice & A & 4 & 2 & 3 & 2 & 5 & 8 & 6 & 6 & 3 & 6 & 4.5 \\
\hline$(n=53)$ & B & 0.409 & 0.021 & 0.399 & 0.413 & 0.715 & 0.848 & 0.313 & 0.365 & 0.414 & 0.723 & 0.46 \\
\hline Late rice & A & 2 & 1 & 4 & 2 & 4 & 4 & 1 & 3 & 4 & 4 & 2.9 \\
\hline$(n=12)$ & B & 0.444 & 0.000 & 0.583 & 0.500 & 0.597 & 0.681 & 0.000 & 0.292 & 0.446 & 0.708 & 0.43 \\
\hline Glutinous rice $\mathrm{S}$ & A & 3 & 1 & 3 & 2 & 1 & 3 & 1 & 6 & 2 & 3 & 2.5 \\
\hline$(n=11)$ & B & 0.512 & 0.000 & 0.562 & 0.320 & 0.000 & 0.579 & 0.000 & 0.810 & 0.496 & 0.645 & 0.39 \\
\hline All Vietnam & A & 4 & 2 & 7 & 2 & 7 & 10 & 8 & 14 & 6 & 12 & 7.2 \\
\hline$(n=222)$ & B & 0.322 & 0.064 & 0.654 & 0.497 & 0.656 & 0.766 & 0.475 & 0.672 & 0.418 & 0.819 & 0.53 \\
\hline
\end{tabular}


Table 5 Nei's genetic distances calculated between eight Vietnamese rice groups
The abbreviations of the groups are the same as shown in Table 3

\begin{tabular}{|c|c|c|c|c|c|c|c|}
\hline \multirow[t]{2}{*}{ Group $^{a}$} & \multicolumn{3}{|c|}{ North Vietnam } & \multicolumn{4}{|c|}{ South Vietnam } \\
\hline & Fifth & Tenth & Glu N & Early & Half & Season & Late \\
\hline Tenth & 0.223 & & & & & & \\
\hline Glu N & 0.493 & 0.389 & & & & & \\
\hline Early & 0.370 & 0.268 & 0.518 & & & & \\
\hline Half & 0.340 & 0.248 & 0.554 & 0.135 & & & \\
\hline Season & 0.355 & 0.365 & 0.681 & 0.096 & 0.092 & & \\
\hline Late & 0.385 & 0.515 & 0.926 & 0.166 & 0.216 & 0.080 & \\
\hline Glu S & 0.433 & 0.510 & 0.986 & 0.223 & 0.280 & 0.154 & 0.127 \\
\hline
\end{tabular}

values to compare the genetic variation within groups and populations.

Evaluation of genetic differentiation among cultivated and wild rice groups

Nei's genetic distance (Nei 1972) was calculated using POPGENE ver. 1.31 (Yeh et al. 1999) to measure genetic differentiation among cultivated groups and wild rice populations. The genetic distances among local variety groups and wild populations were calculated, and unrooted dendrograms were constructed using the UPGMA methods and the program TreeView (Page 1996).

\section{Results and discussion}

Evaluation of genetic variation within Vietnamese local variety groups

Genetic variation within groups was studied based on the dissimilarity of electromorph band patterns using 10 SSR markers. Table 3 shows the average dissimilarity values observed within Vietnamese local variety groups. The overall average dissimilarity among Vietnamese local varieties was 0.51 , indicating that a pair of Vietnamese local varieties chosen randomly may share almost half of the alleles at the ten SSR loci. Among the eight groups, the highest average dissimilarity value (0.49) was observed for "Tenth month rice". According to Hamada (1965), "Tenth month rice" can be further classified into two types. This rice group was planted in nearly $70 \%$ of all rice field in North Vietnam. These observations might explain why "Tenth month rice" maintained a high genetic diversity. Relatively higher values, 0.44 and 0.47 , were observed for "Glutinous rice N" and "Glutinous rice S", respectively. However, the overall average dissimilarity for "Glutinous rice" was 0.59 , indicating geographical differentiation between the two glutinous rice groups. The lowest average dissimilarity, 0.32, was detected for "Fifth month rice". "Fifth month rice", cultivated during the dry season, requires strong lodging resistance before the rainy season and draught tolerance during the vegetative growth period (Hamada 1965). Therefore, limited genotypes might be selected for this rice group. The other South Vietnamese rice groups had moderate dissimilarity values $(0.41-0.45)$, suggesting similar levels of variation within groups, although their growing/ harvesting periods during the rainy season were different.

Genetic variation within groups was also examined based on gene diversity values (Table 4). The relative average values for the eight groups were similar to the average dissimilarity values.

Allelic diversity at SSR loci observed among Vietnamese local varieties

Ten SSR markers were used to examine the genetic variation among the 222 local varieties. Their allelic diversity was examined using gene diversity values, which are identical to the PIC values for self-pollinating plants. In all Vietnamese varieties, the PIC values of the ten SSR markers ranged from 0.064 (RM29) to 0.819 (RM241), and

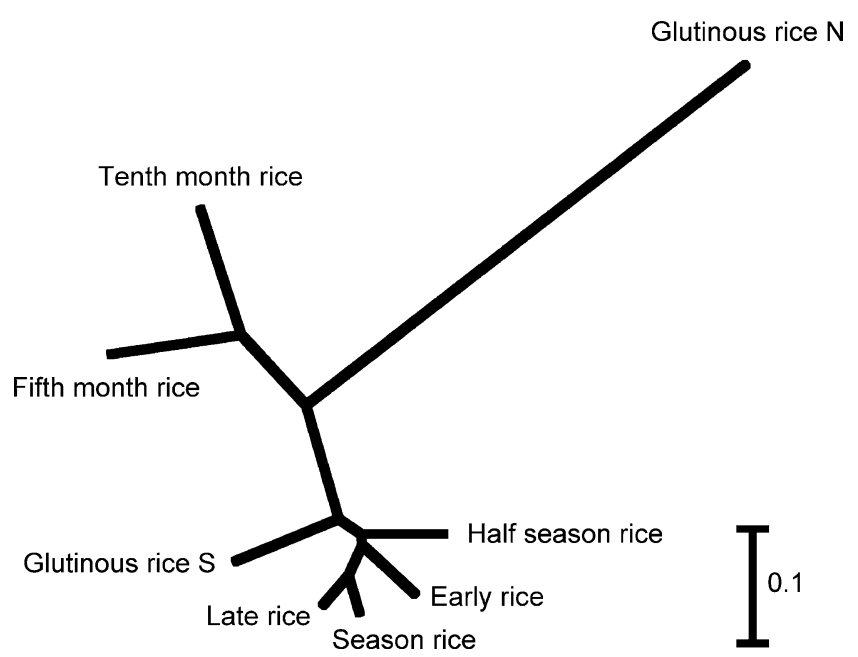

Fig. 2 A phylogenic tree based on Nei's genetic distances among eight Vietnamese rice groups. 
averaged 0.53 . Seven out of the ten SSR markers (all except RM60, RM201, and RM29) were previously used to examine genetic diversity in 23 Asian cultivars of $O$. sativa (Ishii et al. 2001). The average PIC values at the seven SSR loci in this study and the previous study were 0.59 and 0.78 , respectively, suggesting that relatively high levels of polymorphisms were observed among local varieties collected from one country.

Evaluation of genetic differentiation among Vietnamese rice groups

Nei's genetic distances were calculated between all pairs of Vietnamese rice groups to examine their genetic differentiation (Table 5). A higher value indicates greater genetic differentiation between the two groups. Relatively low genetic distance values $(0.080-0.216)$ were observed between common rice groups ("Early rice", "Half season rice", "Season rice", and "Late rice") in South Vietnam. Their close relationships might be due to the partially overlapping crop seasons in the same region. The genetic distance between two North Vietnamese varieties ("Tenth month rice" and "Fifth month rice") was 0.223 , and the highest value of 0.986 was observed between "Glutinous rice N" and "Glutinous rice S". A phylogenic tree was constructed based on the genetic distance values between all pairs (Fig. 2). Two small clusters were generated: one consisted of common South Vietnamese rice groups and "Glutinous rice S", and the other included the North Vietnamese groups ("Tenth month rice" and "Fifth month rice"), suggesting the geographical separation of the rice groups. "Glutinous rice N" showed the widest differentiation from all other groups, and "Glutinous rice S" was located in the outer branch of the South Vietnamese groups. These results suggest that selection based on human preference for rice grain characters had a great influence on the diversification of glutinous rice in Vietnam.

Evaluation of genetic variation within wild rice populations

Leaf samples of wild rice were collected at three sites (PT-1, YG-23, and AK-18) in Myanmar and three (CT-

Table 6 Number of alleles (A), gene diversity (B), and observed heterogenity (C) found in six wild rice populations in Myanmar and Vietnam

\begin{tabular}{|c|c|c|c|c|c|c|c|}
\hline \multirow[t]{2}{*}{ Group } & & \multicolumn{5}{|l|}{ Locus } & \multirow[t]{2}{*}{ Averag } \\
\hline & & $\begin{array}{l}\text { RM31 } \\
\text { (Chr. 5) }\end{array}$ & $\begin{array}{l}\text { RM60 } \\
\text { (Chr. 3) }\end{array}$ & $\begin{array}{l}\text { RM201 } \\
\text { (Chr. 9) }\end{array}$ & $\begin{array}{l}\text { RM208 } \\
\text { (Chr. 2) }\end{array}$ & $\begin{array}{l}\text { RM237 } \\
\text { (Chr. 1) }\end{array}$ & \\
\hline \multicolumn{8}{|l|}{ Myanmar (wild rice) } \\
\hline \multirow[t]{3}{*}{ PT-1 $(n=180)$} & A & 12 & 6 & 10 & 10 & 21 & 11.8 \\
\hline & $\mathrm{B}$ & 0.870 & 0.722 & 0.612 & 0.755 & 0.848 & 0.76 \\
\hline & $\mathrm{C}$ & 0.678 & 0.682 & 0.154 & 0.697 & 0.805 & 0.60 \\
\hline \multirow[t]{3}{*}{ YG-23 $(n=280)$} & A & 7 & 4 & 5 & 4 & 8 & 5.6 \\
\hline & $\mathrm{B}$ & 0.522 & 0.590 & 0.307 & 0.407 & 0.679 & 0.50 \\
\hline & $\mathrm{C}$ & 0.347 & 0.903 & 0.079 & 0.204 & 0.843 & 0.48 \\
\hline \multirow[t]{3}{*}{ AK-18 $(n=156)$} & A & 10 & 2 & 4 & 10 & 7 & 6.6 \\
\hline & B & 0.224 & 0.006 & 0.063 & 0.559 & 0.107 & 0.19 \\
\hline & $\mathrm{C}$ & 0.118 & 0.006 & 0.064 & 0.077 & 0.072 & 0.07 \\
\hline \multicolumn{8}{|l|}{ Vietnam (wild rice) } \\
\hline \multirow[t]{3}{*}{ CT-61 $(n=140)$} & A & 4 & 2 & 8 & 4 & 7 & 5.0 \\
\hline & B & 0.501 & 0.030 & 0.707 & 0.618 & 0.626 & 0.50 \\
\hline & $\mathrm{C}$ & 0.711 & 0.030 & 0.114 & 0.985 & 0.962 & 0.56 \\
\hline \multirow[t]{3}{*}{ CT-65 $(n=80)$} & A & 3 & 3 & 3 & 6 & 5 & 4.0 \\
\hline & $\mathrm{B}$ & 0.485 & 0.372 & 0.249 & 0.683 & 0.704 & 0.50 \\
\hline & $\mathrm{C}$ & 0.000 & 0.354 & 0.000 & 0.949 & 0.962 & 0.45 \\
\hline \multirow[t]{3}{*}{ CT-67 $(n=140)$} & A & 16 & 7 & 15 & 11 & 21 & 14.0 \\
\hline & B & 0.891 & 0.698 & 0.871 & 0.795 & 0.784 & 0.81 \\
\hline & $\mathrm{C}$ & 0.820 & 0.625 & 0.712 & 0.829 & 0.609 & 0.72 \\
\hline \multirow[t]{3}{*}{ Vietnam (local varieties) $(n=222)$} & A & 7 & 2 & 7 & 10 & 6 & 6.4 \\
\hline & B & 0.654 & 0.497 & 0.656 & 0.766 & 0.418 & 0.60 \\
\hline & $\mathrm{C}$ & 0.000 & 0.005 & 0.005 & 0.023 & 0.005 & 0.01 \\
\hline
\end{tabular}


Table 7 Nei's genetic distances calculated between six wild rice populations

\begin{tabular}{llllllll}
\hline \multirow{2}{*}{ Group } & \multicolumn{2}{l}{ Myanmar } & & & \multicolumn{2}{l}{ Vietnam } \\
\cline { 2 - 4 } \cline { 6 - 7 } & PT-1 & YG-23 & AK-18 & & CT-61 & CT-65 & CT-67 \\
\hline PT-1 & - & & & & & \\
YG-23 & 0.318 & - & & & & \\
AK-18 & 1.670 & 1.372 & - & & & \\
CT-61 & 1.138 & 2.021 & 2.281 & - & & \\
CT-65 & 1.677 & 3.059 & 2.353 & 0.617 & - & \\
CT-67 & 0.505 & 0.917 & 1.097 & 0.886 & 0.678 & - \\
\hline
\end{tabular}

61, CT-65, and CT-67) in Vietnam. Based on the electromorph allele data, the number of alleles over the five SSR loci, gene diversity (corresponding to the expected heterozygosity), and the observed heterozygosity were calculated for each population (Table 6). Among the six populations investigated, high average gene diversity values were observed for the PT-1 (0.76) and CT-67 (0.81) populations, whereas low values were calculated for AK-18 (0.19). The PT-1 and CT-67 habitats were deepwater areas, and these populations were huge. No disturbance (e.g., animal grazing or human cutting) was observed in the population. Therefore, the high levels of genetic variation might be maintained by clonal propagation under stable environmental conditions. By contrast, the wild rice plants at AK-18 were typical annual forms, and they propagated solely through seed. The observed heterogeneity was quite low (0.07), indicating that most of the plants were fixed to homozygote forms in

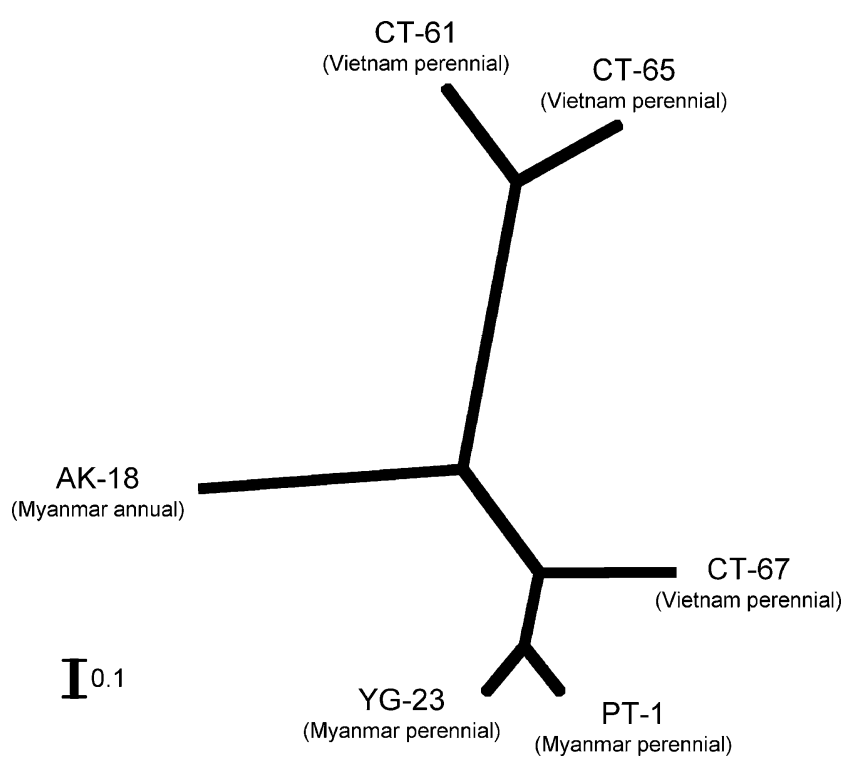

Fig. 3 A phylogenic tree based on Nei's genetic distances among six wild rice populations in Myanmar and Vietnam. annual populations. This would cause low genetic variation within a small self-pollinated population.

Genetic differentiation among wild rice populations in Myanmar and Vietnam

The genetic differentiation among wild rice populations in Myanmar and Vietnam was calculated based on the genetic distances between them (Table 7). Using these values, a phylogenic tree was constructed as shown in Fig. 3. The three populations each in Myanmar and Vietnam did not form clear geographical groups. The annual AK-18 population showed marked differentiation from the others, and the two populations at PT-1 and CT-67, with higher genetic variation within populations, made a small cluster. These results indicate that ecological factors had a much greater influence on genetic differentiation among the wild rice populations than did geographical factors.

Comparison of genetic variation between wild rice and local varieties

To compare the degrees of genetic variation in wild rice and local varieties, the overall number of alleles and gene diversity were calculated for five common microsatellite loci (RM31, RM60, RM201, RM208, and RM237) in the 222 Vietnamese local varieties (Table 6). The number of alleles ranged from two to ten, with an average of 6.4 , and the gene diversity was $0.418-0.766$, and averaged 0.60 . Although local cultivars were collected from various areas in Vietnam, these average values were less than those detected at PT-1 (11.8 for average number of alleles, and 0.76 for average gene diversity) and CT-67 (14.0, and 0.81 ). In particular, only 140 wild plants were surveyed at a single site of CT-67 in Vietnam, and the numbers of alleles and the gene diversity values at five loci were all higher than those in Vietnamese local varieties (Table 6). In addition, wide genetic differentiation was observed among wild rice populations in Myanmar and Vietnam (Fig. 3). These results indicate that wild rice has much higher genetic variation than cultivated rice.

Acknowledgments We thank Dr. Tin Htut and Mr. Minn San Thein, Department of Agricultural Research, Myanmar, and Dr. Nguyen Thi Lang, Cuulong Delta Rice Research Institute, Vietnam, for their kind research collaboration on wild rice survey.

\section{References}

Cai HW, Wang XK, Morishima H. Comparison of population genetic structures of common wild rice (Oryza rufipogon Griff.), as revealed by analyses of quantitative traits, allozymes, and RFLPs. Heredity. 2004;92:409-17. 
Chen X, Temnykh S, Xu Y, Cho YG, McCouch SR. Development of a microsatellite framework map providing genome-wide coverage in rice (Oryza sativa L.). Theor Appl Genet. 1997;95:553-67.

Gao L. Population structure and conservation genetics of wild rice Oryza rufipogon (Poaceae): a region-wide perspective from microsatellite variation. Mol Ecol. 2004;13:1009-24.

Hamada H. Rice in Mekong valleys. In: Indo-Chinese studies, Synthetic research of the culture of rice-cultivating races in Southeast Asian countries. The Japanese Society of Ethnology (Tokyo). 1965;1:507-586

Ishii T, Xu Y, McCouch SR. Nuclear- and chloroplast-microsatellite variation in a genome species of rice. Genome. 2001;44:658-66.

McCouch SR, Chen X, Panaud O, Temnykh S, Xu Y, Cho YG, et al. Microsatellite marker development, mapping and applications in rice genetics and breeding. Plant Mol Biol. 1997;35:89-99.

Nei M. Genetic distance between populations. Am Nat. 1972;106:283-92.

Nei M. Molecular evolutionary genetics. New York: Columbia University Press; 1987.

Nei M, Li WH. Mathematical model for studying genetic variation in terms of restriction endonuclease. Proc Natl Acad Sci USA. 1979;76:5269-73.

Oka H. The ancestors of cultivate rice. In: Origin of cultivated rice. Tokyo: Japan Scientific Societies Press; 1988. p. 15-24

Page RDM. TREEVIEW: an application to display phylogenic trees on personal computers. Comput Appl Biosci. 1996;12:357-8.

Panaud O, Chen X, McCouch SR. Development of microsatellite markers and characterization of simple sequence length polymorphism (SSLP) in rice (Oryza sativa L.). Mol Gen Genet. 1996;252:597-607.
Song ZP, Xu X, Wang B, Chen JK, Lu BR. Genetic diversity in the northernmost Oryza rufipogon populations estimated by SSR markers. Theor Appl Genet. 2003;107:1492-9.

Sun CQ, Wang XK, Yoshimura A, Doi K. Genetic differentiation for nuclear, mitochondrial and chloroplast genomes in common wild rice (Oryza rufipogon Griff.) and cultivated rice (Oryza sativa L.). Theor Appl Genet. 2002;104:1335-45.

Tanksley SD, McCouch SR. Seed banks and molecular maps: unlocking genetic potential from the wild. Science. 1997;277:1063-6.

Tanksley SD, Grandillo S, Fulton TM, Zamir D, Eshed Y, Petiard V, et al. Advanced backcross QTL analysis in a cross between an elite processing line of tomato and its wild relative L. pimpinellifolium. Theor Appl Genet. 1996;92:213-24.

Temnykh S, DeClerck G, Lukashova A, Lipovich L, Cartinhour S, McCouch SR. Computational and experimental analysis of microsatellites in rice (Oryza sativa L.): frequency, length variation, transposon associations, and genetic marker potential. Genome Res. 2001;11:1441-52.

Xiao J, Li J, Grandillo S, Ahn SN, Yuan L, Tanksley SD, et al. Genes from wild rice improve yield. Nature. 1996;384:223-4.

Xiao J, Li J, Grandillo S, Ahn SN, Yuan L, Tanksley SD, et al. Identification of trait-improving quantitative trait loci alleles from a wild rice relative, Oryza rufipogon. Genetics. 1998;150:899-909.

Yeh FC, Yang RC, Boyle T. POPGENE. Microsoft windows-based freeware for population genetic analysis. Release 1.31. University of Alberta, Edmonton; 1999

Zhou HF, Xie ZW, Ge S. Microsatellite analysis of genetic diversity and population genetic structure of a wild rice (Oryza rufipogon Griff.) in China. Theor Appl Genet. 2003;107:332-9. 